\title{
PENINGKATAN EFISIENSI TEMPAT PENYIMPANAN DOKUMEN DENGAN MENGGUNAKAN METODE 5S DAN SIKLUS PDCA DI INDUSTRI FARMASI
}

\author{
MRR. Dwi Lindawati ${ }^{1}$, Hery Hamdi Azwir ${ }^{2 *}$ \\ 1 PT Dexa Medica, Jababeka, Cikarang, Bekasi \\ 2 Program Studi Teknik Industri, Fakultas Teknik, President University \\ Email: lindawati.dwi@gmail.com; hery.azwir@president.ac.id
}

Artikel masuk : 02-08-2021

Artikel direvisi : 30-09-2021

Artikel diterima : 20-10-2021

${ }^{*}$ Penulis Korespondensi

\begin{abstract}
Abstrak -- Pusat penelitian dan pengembangan obat yang ada di PT Dexa Medica adalah Dexa Development Center (DDC). Output dari DDC adalah dokumen dan disimpan dalam tempat penyimpanan yang dinamakan Kardex Remstar Shuttle XP 500. Pada periode 2019 - 2020 ditemukan penumpukkan dokumen di dalam kardex sebesar 4529 ordner, area kosong yang tersisa 171, diluar kardex 550 ordner, ruang tempat penyimpanan menjadi tidak rapi, membutuhkan waktu yang lama saat mencari dokumen, tidak ada penambahan area dan sistem pengelolaan dokumen belum dilakukan proses pemusnahan. Dengan adanya masalah tersebut dilakukan perbaikan dengan analisis siklus PDCA dan 5S sebagai langkah yang dilakukan pada do. Hasil dari analisis siklus PDCA adalah dokumen di dalam kardex berkurang dari 290 ordner terdapat 45 ordner atau 16\% musnah, area kosong meningkat dari 171 menjadi 216 ordner atau 21\% dan secara total meningkat dari 4529 menjadi 4908 atau 104\%. Jumlah ordner di luar kardex berkurang dari 550 menjadi 126 ordner atau 77,09\%. Dengan penggantian ordner menghemat biaya sebesar Rp 5.168 .160 atau 79,90\%. Menghemat waktu pencarian dokumen di luar kardex dari 510 detik menjadi 33 detik atau 94\%. Pengelolaan dokumen agar tetap dijalankan supaya tidak terjadi penumpukan dan tempat penyimpanan dapat dimanfaatkan secara optimal.
\end{abstract}

Kata kunci: 5S; Pengelolaan Dokumen; Siklus PDCA; Tempat Penyimpanan

\begin{abstract}
The drug research and development center at PT Dexa Medica is the Dexa Development Center (DDC). The output of $D D C$ is documents and stored in a storage area called the Kardex Remstar Shuttle XP 500. In the 2019 - 2020 period, it was found that the accumulation of documents in the kardex amounted to 4529 ordner, the remaining empty area was 171, outside the kardex 550 ordner, the storage space became untidy, it takes a long time when searching for documents, there is no additional area and the document management system has not been destroyed. With these problems, improvements were made by analyzing the PDCA and 5S cycles as steps taken. The result of the PDCA cycle analysis is that documents in the kardex decreased from 290 ordners, where 45 ordner were destroyed, or $16 \%$ were destroyed, the empty area increased from 171 to 216 ordner or $21 \%$ and the total increased from 4529 to 4908 or $104 \%$. The number of ordners outside the kardex decreased from 550 to 126 ordners or $77.09 \%$. By replacing ordner, it saves costs of Rp. $5,168,160$ or $79.90 \%$. Save time looking for documents outside kardex from 510 seconds to 33 seconds or $94 \%$. Document management should continue to be carried out so that there is no accumulation and the storage area can be used optimally.
\end{abstract}

Keywords: 5S; Document Management; PDCA Cycle; Storage 


\section{PENDAHULUAN}

Dalam setiap organisasi yang dinamis, tuntutan untuk menyesuaikan diri terhadap perubahan selalu muncul. Demikian halnya dengan industri yang selalu bertumbuh, kebutuhan akan selalu meningkat, sehingga mengakibatkan dibutuhkan suatu sistem yang dapat memelihara agar perusahaan tetap tumbuh meskipun dinamika selalu terjadi. Salah satu sistem yang dapat memelihara perusahaan agar dapat menjaga mutu adalah sistem manajemen mutu. Ada banyak sekali sistem manajemen mutu yang dikenal dari yang memiliki konsep sederhana misalkan 5S, PDCA, lebih advanced lagi misalnya DMAIC, atau berupa sistem yang lebih terintegrasi dan bisa mendapatkan sertifikasi misalkan seri-seri ISO, dan masih banyak lagi yang lainnya. Pemilihan metode yang tepat tentu harus disesuaikan dengan kebutuhan dan kemampuan sumber daya yang dimiliki dan skala yang menjadi fokus perhatian.

Setiap perusahaan pasti memiliki ruang penyimpanan barang dan dokumen yang setiap harinya terus bertambah dan pada akhirnya ruang semakin sempit dan tidak dapat menampungnya. PT Dexa Medica adalah perusahaan farmasi. Pusat penelitian dan pengembangan obat yang ada di PT Dexa Medica adalah Dexa Development Center (DDC) yang berlokasi di Cikarang, Bekasi. DDC merupakan tempat pengembangan produk dengan output yang dihasilkan adalah dokumen penting dari pengembangan obat. Dokumen yang ada di DDC masih dikelola dengan dua cara yaitu dokumen yang dikelola secara manual dan dokumen yang dikelola secara digital dikarenakan tidak semua dokumen dapat dialihkan ke dalam bentuk digital.

Dokumen dalam bentuk digital dalam format scan pdf dikelola dalam sebuah aplikasi web yang bernama Infotehna. Dokumen dalam bentuk manual disimpan dalam tempat penyimpanan yang dinamakan Kardex Remstar Shuttle XP 500. Pada periode tahun 2019 - 2020 ditemukan penumpukan dokumen di dalam Kardex sebesar 4529 ordner, area kosong yang tersisa di dalam Kardex hanya 171 dan diluar Kardex sebesar 550 ordner. Selain penumpukan juga ditemukan masalah lain yaitu, ruang tempat penyimpanan menjadi tidak rapi, membutuhkan waktu yang lama saat mencari dokumen, tidak ada penambahan area sehingga harus memanfaatkan area yang sudah tersedia dan sistem pengelolaan dokumen belum dilakukan proses pemusnahan dokumen yang sudah melewati masa simpan dikarenakan belum adanya data umur dari masing-masing dokumen.

Untuk menyelesaikan permasalahan ini dan mempertimbangkan kemampuan sumber daya yang dimiliki, PDCA menjadi pilihan dan kemudian memadukannya dengan konsep 5S. Meskipun PDCA adalah konsep dan metode yang sudah lama diperkenalkan, namun keefektifannya masih diakui hingga sekarang (Isniah et al., 2020). Sedangkan 5S awalnya didasarkan pada akronim Jepang seiri (pemilahan), seiton (penataan), seiso (pembersihan), seiketsu (pemantapan) dan shitsuke (pembiasaan), yang digunakan sebagai platform untuk mengembangkan sistem manajemen terintegrasi dan dengan penggunaan TPM (Gapp et al., 2008).

Sejumlah penelitian terbaru tetap mengakui keefektifan PDCA diantaranya dalam industri manufaktur yaitu untuk menurunkan cacat scratch di lini perakitan frame industri kendaraan bermotor (Nelfiyanti et al., 2020), pengendalian kualitas pengelasan blast furnace shell (Wajdi \& Wiguna, 2015), perbaikan mutu pengecatan di area painting shop PT Toyota Motor Manufacturing Indonesia (Adyatama \& Handayani, 2018), penurunan cacat yang terjadi pada feed roll di perusahaan manufaktur tool dan perkakas (Azwir \& Setyanto, 2017), menurunkan cacat pada proses penempelan elemen baterai kendaraan bermotor (Darmawan et al., 2018) dan dalam aplikasi upaya peningkatan produktivitas tenaga kerja (Azwir \& Satriawan, 2018).

Contoh kasus selain manufaktur adalah dalam dunia kesehatan, ternyata PDCA juga efektif diaplikasikan diantaranya, untuk pengelolaan manajemen rumah sakit melalui hospital information management system dan quality management of clinical nursing work (Jiang et al., 2021; Kaniecka et al., 2021), PDCA-based nursing intervention (Huang et al., 2021), dan pengembangan alat bantu untuk menangani kepadatan pasien di IGD (Kusumawardhani et al., 2021). PDCA juga dapat membantu dalam implementasi keamanan sistem informasi melalui security education, training and awareness (De Casanove \& Sèdes, 2021).

Analisis dengan pendekatan siklus PDCA digunakan sebagai alat untuk mengontrol penerapan setiap langkah dari 5S (Kumar \& Kumar, 2012). Studi ini bertujuan untuk memperlihatkan bahwa PDCA dan 5S dapat digunakan juga untuk mengoptimalkan tempat penyimpanan dokumen dan siklus keluar masuknya dokumen agar tetap terus berjalan dan pengelolaan dokumen menjadi lebih sistematis.

\section{METODE PENELITIAN}

Dokumen sangat penting dalam memberikan kemudahan dalam pelayanan dan informasi kepada yang membutuhkan dalam sebuah organisasi (Fajri \& Syahyuman, 2012). Pengelolaan dokumen dapat diartikan sebagai tata cara 
mengolah semua sumber informasi agar dapat tersimpan dengan aman dan dapat ditemukan dengan mudah dan cepat pada saat dibutuhkan. Pengelolaan arsip secara digital adalah suatu cara mengolah arsip dengan mengalihkan media arsip menjadi media baru yang berupa hasil scanner sehingga secara fisik arsip dapat diselamatkan (Muhidin et al., 2016).

Metode dan tools yang digunakan dalam penelitian ini adalah 5S, siklus PDCA, pareto chart dan flowchart. Teknik pengumpulan data diperoleh dengan cara wawancara langsung ke area tempat penyimpanan dokumen. Langkah dalam penelitian ini dipaparkan dalam sebuah alur yang dapat dilihat pada Gambar 1 .

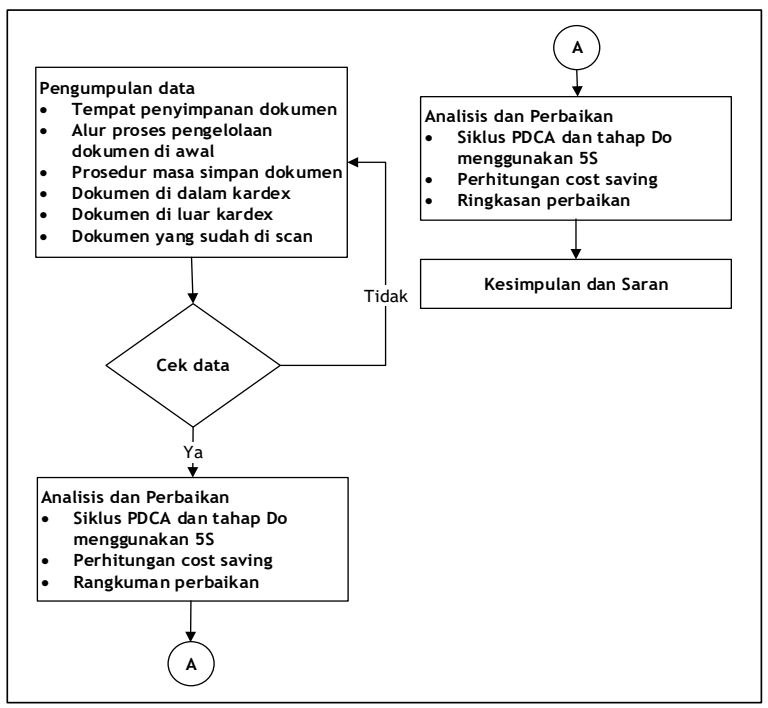

Gambar 1. Alur Langkah Penelitian

5S sangat mudah dan efektif dalam meningkatkan operasi kerja. Pengertian dari 5S adalah alat untuk mengurangi suatu proses kerja kemudian dijadikan standar kerja. $5 \mathrm{~S}$ berasal dari bahasa Jepang yang memiliki 5 tahap yaitu Sort (Seiri), Set in Order (Seiton), Shine (Seiso), Standardize (Seiketsu), Sustain (Shitsuke) (Visco, 2017). Salah satu aktivitas dalam lean manufacturing adalah $5 S$ yang berfungsi untuk mengefisienkan proses kerja dengan cara mengatur, menstandarkan dan mengurangi waktu yang terbuang (Agrahari et al., 2015).

Siklus PDCA merupakan siklus perbaikan proses secara terus menerus yang didasarkan pada metode ilmiah yang awalnya disebut dengan siklus Shewhart yang dikembangkan oleh Walter A. Shewhart. Pada tahun 1950-an Jepang memberikan nama siklus Deming. Siklus PDCA terdiri dari 4 tahap dasar: plan, do, check and action (Mitra, 2016). Siklus PDCA digunakan sebagai alat untuk menguji dan melakukan perubahan terhadap perbaikan sistem, proses dan kinerja produk di masa yang akan datang. Siklus PDCA merupakan sebuah metode pemecahan masalah yang bersifat iteratif dan dapat diaplikasikan dalam mengendalikan kualitas secara statistik dan terus menerus atau disebut dengan perbaikan kaizen (Azwir \& Satriawan, 2018).

Siklus PDCA dapat digunakan sebagai alat untuk menganalisis dan mengontrol penerapan setiap langkah dari 5S (Kumar \& Kumar, 2012). Dalam penelitian ini, aktivitas yang dilakukan pada masing-masing tahap siklus PDCA adalah sebagai berikut:

Plan: Sebelum ke tahap implementasi, pelatihan 5S harus disediakan untuk semua anggota dalam sebuah organisasi. Kemudian dibentuk Dewan 5S yang berfungsi untuk menetapkan zona $5 S$ dan menentukan tujuan, sasaran, dan fase implementasi 5S.

Do: Pada tahap ini dilakukan penerapan dari masing-masing $5 S$ yaitu:

a. Sort

Mengidentifikasi item yang diperlukan. Untuk menerapkanya dapat dilakukan dengan memberikan Red-tag untuk membantu mengidentifikasi item yang tidak diinginkan dan menentukan kegunaanya.

b. Set in Order

Setelah mengidentifikasi item yang diperlukan kemudian mengatur atau menyusun yang diperlukan untuk hal yang sama. Pemberian label memudahkan orang lain ketika pemilik sedang pergi dan manfaatnya adalah untuk mengurangi waktu pencarian.

c. Shine

Mengidentifikasi sumber kotoran bersama dengan akar penyebabnya. Pembersihan area kerja perlu dilakukan setiap hari untuk mempertahankan tempat kerja yang bebas dari kekacauan dan lingkungan yang tak diinginkan.

d. Standardize

Setelah menyusun rencana tindakan, penugasan tanggung jawab diidentifikasi dan dilaksanakan. Setelah $3 \mathrm{~S}$ (sort, set in order, shine) diterapkan maka langkah selanjutnya adalah membuat prosedur dan daftar periksa harian sederhana yang harus ditampilkan secara jelas di setiap tempat kerja.

e. Sustain

Melatih dan mendidik setiap orang agar dapat mengerti, mematuhi dan mempraktikkan aturan dan prosedur yang berlaku, membiasakan untuk menjaga keempat $S$ sebelumnya untuk memastikan keberlanjutan sistem dan melakukan perbaikan siklus P-D-CA yang efektif. 
Check: Pada tahap ini dilakukan penilaian sejauh mana penerapan tersebut dapat dilakukan dengan melakukan audit 5S internal. Memeriksa hasil setelah dilakukan tahap do.

Action: Pada tahap ini untuk perbaikan berkelanjutan, personel terkait harus mengembangkan praktik $5 S$ menjadi suatu kebiasaan. Secara berkala tujuan yang sebenarnya harus dibandingkan dengan tujuan yang ditetapkan. Untuk memotivasi orang, dapat dilakukan dengan memberikan penghargaan. Gambar 2 mengilustrasikan peta jalan untuk memastikan penerapan 5S berjalan dengan sukses.

Pareto chart dapat membantu memberikan prioritas pemecahan masalah dengan mengaturnya dalam urutan yang menurun dimana setiap batang mewakili masalah yang berbedabeda kategori (Mitra, 2016). Dimana yang berkontribusi paling tinggi dapat dilihat pada batang tertinggi. Flowchart sangat membantu dalam memvisualisasikan dan mendefinisikan proses sehingga aktivitas tidak bernilai tambah dapat diidentifikasi (Realyvásquez-Vargas et al., 2018). Tools ini diaplikasikan dalam pengolahan data dan analisis.

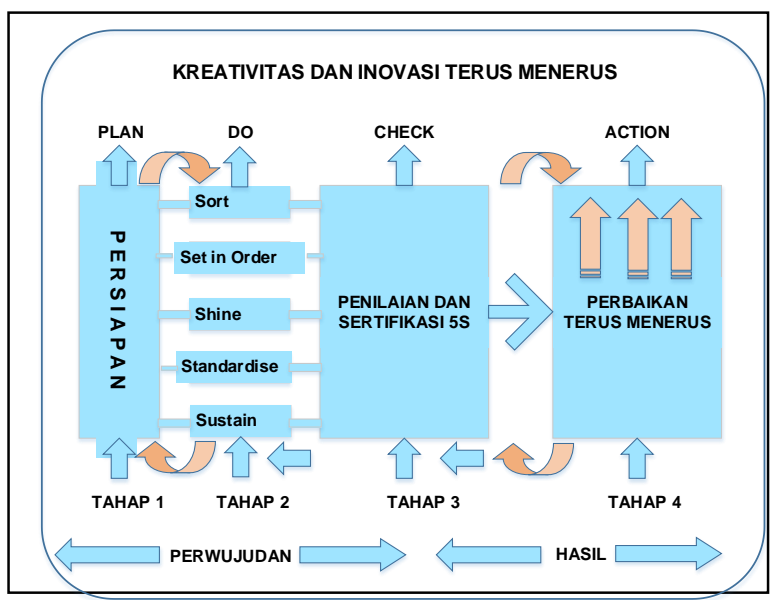

Gambar 2. Peta Jalan Penerapan $5 S$ dengan Siklus PDCA (Kumar \& Kumar, 2012)

Semua industri baik jasa maupun produksi dapat menerapkan Lean Manufacturing sebagai alat untuk mengurangi dan menghilangkan pemborosan dengan cara yang sederhana, layak, handal, hemat biaya, dan sinergis dengan program lain (Agrahari et al., 2015).

\section{HASIL DAN PEMBAHASAN}

Ruang tempat penyimpanan dokumen di DDC dibangun dengan ukuran $5500 \times 11000 \times$ $3000 \mathrm{~mm}$ dan dirancang dengan ruangan yang tahan api atau double wall, karena dokumen yang ada di DDC merupakan dokumen penting yang dijaga kerahasiaan dan keamanannya. Tempat penyimpanan dokumen dinamakan Kardex Remstar Shuttle XP 500 (Gambar 3). Kardex tersebut memiliki kapasitas sebanyak 4700 ordner dengan ukuran standard, terdapat 58 tray dengan ketinggian 3 lantai dan ukuran 3380 x 3074 x $12000 \mathrm{~mm}$.

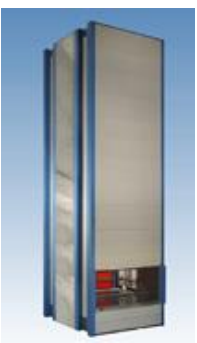

Gambar 3. Kardex Remstar Shuttle XP 500

Alur proses pengelolaan dokumen yang ada di tempat penyimpanan dokumen dapat dilihat pada Gambar 4.

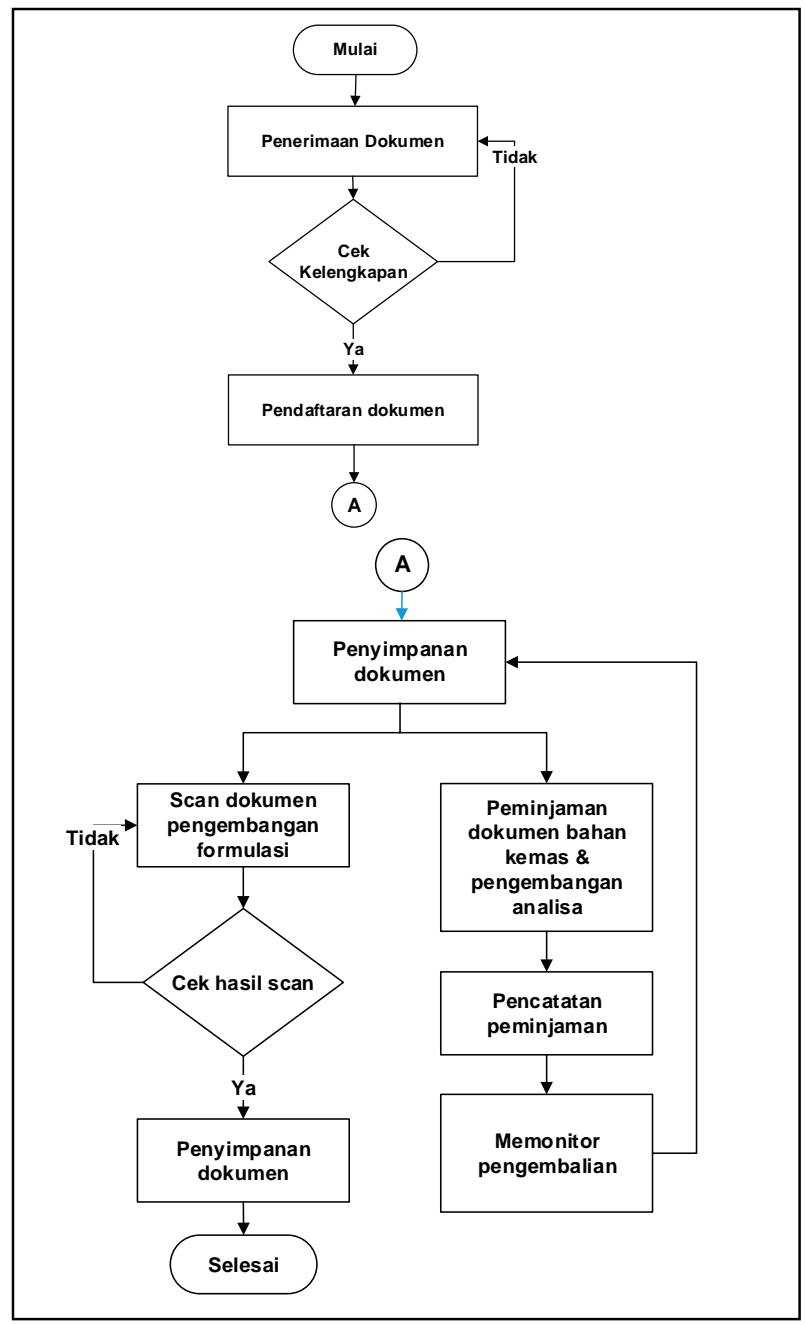

Gambar 4. Alur Proses Pengelolaan Dokumen di Awal 
Prosedur terkait dokumen yang berlaku di DDC yaitu master list record. Di dalam masterlist record berisikan informasi judul dokumen, nomor dokumen, metode simpan, PIC (person in charge), masa simpan, lokasi simpan dan metode pemusnahan. Prosedur tersebut sudah mengatur masa simpan dokumen dari 3 tahun, 5 tahun dan 10 tahun, akan tetapi belum dijalankan proses pemusnahan sesuai dengan masa simpan masing-masing dokumen, dikarenakan belum ada database masa simpan dokumen di dalam Kardex. Hal tersebut berdampak pada kapasitas dokumen di dalam Kardex menjadi overload artinya sudah tidak dapat menampung dokumen baru.

Dokumen yang ada di dalam Kardex periode tahun 2012 hingga 2019. Secara keseluruhan terlihat bahwa jumlah dokumen setiap tahun terus meningkat hingga mendekati batas maksimal kapasitas penyimpanan di dalam kardex yaitu di tahun 2019 sudah mencapai 4529 yang artinya hanya tersisa area kosong saat ini sebanyak $4700-4529=171$ ordner (Gambar 5).

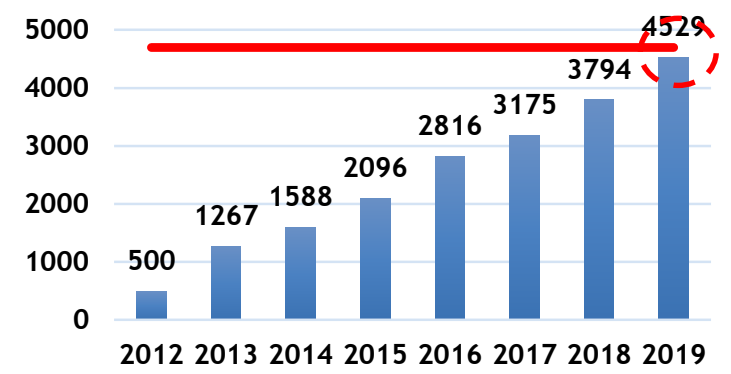

$$
\text { Jumlah Ordner } \longrightarrow \text { Kapasitas }
$$

Gambar 5. Jumlah Ordner di dalam Kardex Periode 2012-2019

Dokumen yang ada di luar Kardex merupakan penerimaan dokumen dari beberapa bagian di DDC antara lain Formulation, Analytical dan Packaging. Pada periode 2019 hingga April 2020 dokumen yang ada di luar Kardex sudah mencapai 550 ordner untuk beberapa jenis dokumen. Bagian Formulation dengan jenis dokumen pengembangan formulasi terdapat 152 ordner, bagian Analytical dengan jenis dokumen pengembangan analisa terdapat 56 ordner dan bagian Packaging dengan jenis dokumen kemasan terdapat 342 ordner.

Dokumen yang ada di dalam Kardex sebanyak 4529 ordner memiliki beberapa status dokumen yang sudah discan dan yang belum di scan antara lain launching (dokumen kemasan) sebanyak 1454 ordner, sudah scan (dokumen pengembangan formulasi) sebanyak 1302 ordner, FINISH (dokumen pengembangan formulasi) sebanyak 1184 ordner, belum scan (dokumen pengembangan formulasi dan analisa) sebanyak 407 ordner dan tidak scan (literature, WI, dokumen gedung dil) sebanyak 182 ordner. Launching artinya dokumen kemasan berupa color range yang akan disimpan sampai ada versi terbaru. Sudah scan artinya dokumen pengembangan formulasi yang sudah di scan akan tetapi belum direview kelengkapannya. FINISH artinya dokumen pengembangan formulasi yang sudah di scan dan sudah melalui tahap review. Belum scan artinya dokumen pengembangan formulasi dan analisa yang belum melalui tahap scan. Tidak scan artinya dokumen yang tidak di scan seperti literature yang belum diatur masa simpannya dalam masterlist record. Pengecekan masa simpan dan pemusnahan tahap awal adalah status FINISH.

Analisis perbaikan dari masing-masing tahap siklus PDCA dalam mengoptimalkan tempat penyimpanan adalah sebagai berikut.

\section{Plan}

Tahap awal siklus PDCA ini dimulai dengan menentukan tujuan dan target yang akan dicapai dengan cara mengenali kemungkinan peluang apa saja untuk melakukan berbagai macam perbaikan. Sebelum menerapkan $5 S$ dilakukan pelatihan $5 S$ kepada semua anggota di bagian system and document management dengan tujuan agar semua anggota dapat berpartisipasi dalam aktivitas $5 \mathrm{~S}$.

Tujuan dan target yang akan dicapai dalam mengoptimalkan tempat penyimpanan adalah sebagai berikut: (1) mengurangi jumlah ordner di dalam kardex, (2) meningkatkan area kosong di dalam kardex, (3) mengurangi jumlah ordner di luar kardex, (4) mengurangi waktu pencarian dokumen

\section{Do}

Pada tahap kedua dari siklus PDCA ini adalah melakukan penerapan dari masing-masing $5 S$ dari setiap tujuan yang akan dicapai dari tahap Plan.

\section{Penerapan 5S Sort (Seiri)}

Jadwal Retensi Arsip (JRA) adalah komponen utama dalam program manajemen arsip karena menentukan efisiensi dan efektifitas dari penyusunan arsip itu sendiri. JRA membahas mengenai arsip yang bersifat dinamis dan statis (Suprayitno \& Sumarno, 2019). Arsip dinamis sudah ditentukan umurnya yang memberi informasi berapa lama masa aktif dan nonaktifnya. Setelah itu diputuskan apakan dimusnahkan, diaktifkan kembali atau dilestarikan di lembaga kearsipan (arsip statis).

Hal yang dapat diterapkan dalam tahap 1 dari $5 S$ ini yaitu sort dengan cara memilah dokumen yang sudah melewati masa simpan 
lebih dari atau sama dengan 10 tahun dari tanggal terakhir dokumen sesuai dengan aturan dalam masterlist record dan mengelompokkan dokumen sesuai dengan jenis dokumen (Tabel 1).

Tabel 1. Penerapan 5S Sort (Seiri)

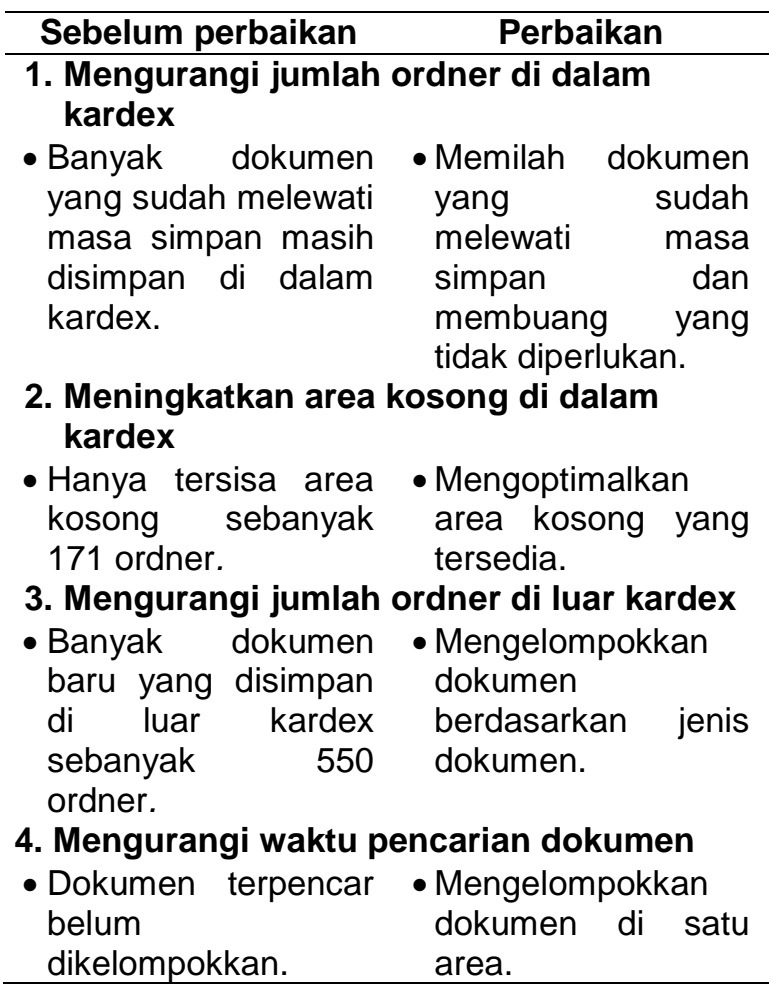

Langkah pertama yang dilakukan adalah dengan cara cek masa simpan dokumen di dalam kardex dengan status FINISH dan membuat list database masa simpan dokumen. Hasil dari pengecekan masa simpan dari pengecekan masa simpan 7 tray dengan total 290 ordner ditemukan 45 ordner dengan masa simpan $\leq 2010$ atau sekitar $16 \%$ yang sudah melewati masa simpan dan dapat dimusnahkan, sisanya 245 ordner dengan masa simpan > 2010 atau sekitar $84 \%$ dokumen dapat disimpan kembali. Gambar 6 memperlihatkan aktivitas yang dilakukan adalah mengelompokkan dokumen sesuai dengan 3 jenis dokumen yaitu pengembangan formulasi, pengembangan analisa dan kemasan.

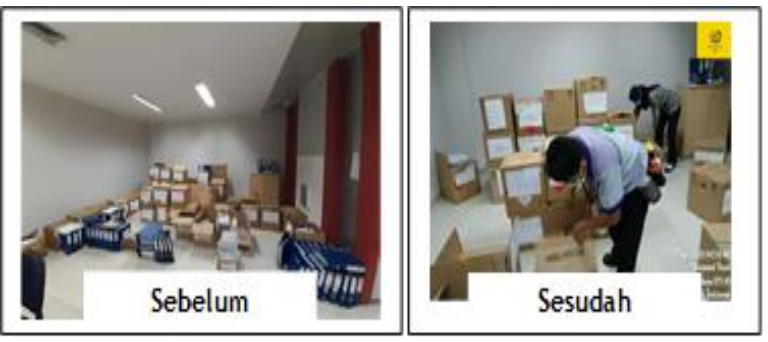

Gambar 6. Dokumen di Luar Kardex Sebelum dan Sesudah

\section{Penerapan 5S Set in Order (Seiton)}

Muhidin et al. (2016) mengatakan bahwa pengelolaan arsip menyangkut dua hal yaitu penyimpanan arsip dan penemuan kembali arsip tersebut. Penyimpanan arsip berkaitan dengan bagaimana arsip tersebut disimpan dalam media apa. Sedangkan penemuan kembali arsip berkaitan erat dengan bagaimana arsip-arsip tersebut diberikan suatu identifikasi sehingga memudahkan untuk ditemukan.

Hal yang dapat diterapkan dalam tahap 2 dari $5 S$ ini yaitu seiton dengan cara mengatur atau menempatkan dokumen yang diperlukan secara rapi dan sistematis. Dengan penempatan yang sistematis yaitu menata dokumen ke dalam kategori masing-masing, diberikan identitas seperti label berwarna, kode nomor item pada wadah dan dokumennya, sehingga akan lebih cepat dan mudah untuk mengidentifikasi lokasi dokumen. Beberapa penerapan seiton dalam mengoptimalkan tempat penyimpanan dokumen di kardex dapat dilihat pada Tabel 2.

Tabel 2. Penerapan 5S Set in Order (Seiton)

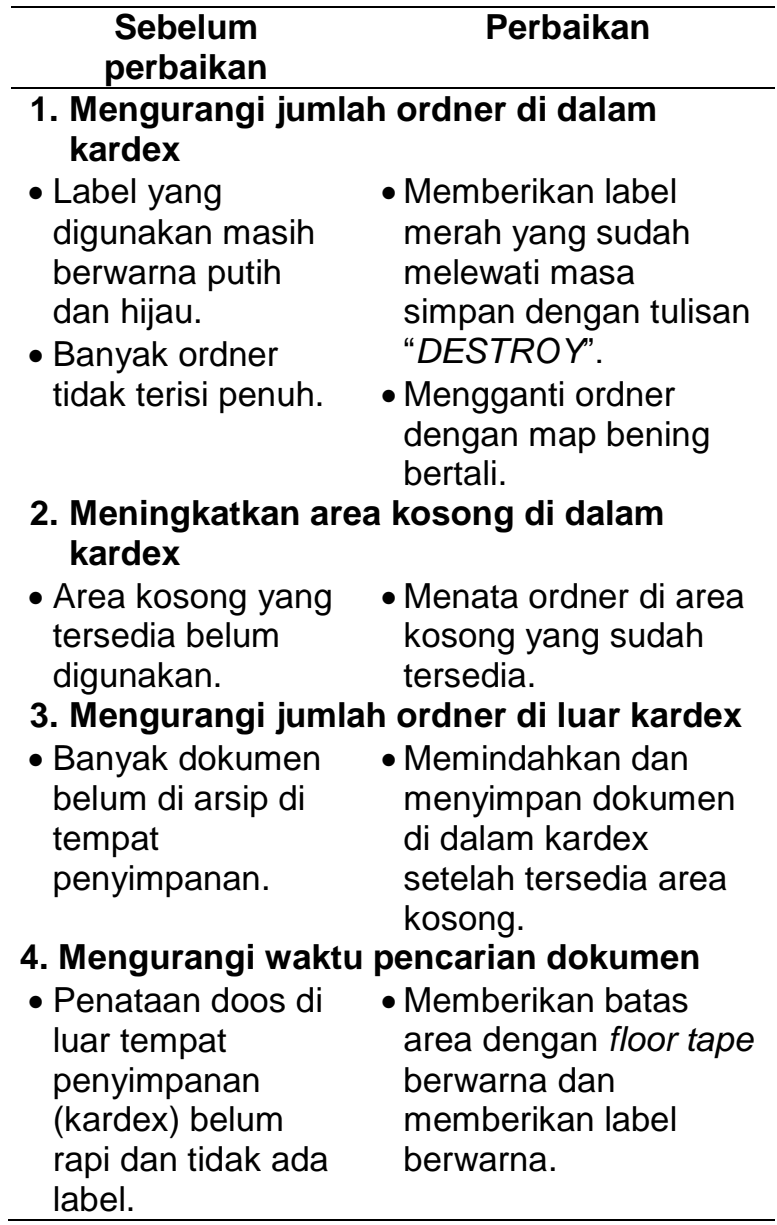

Pada Gambar 7 terlihat yang dilakukan adalah dokumen yang sudah dicek masa simpannya habis kemudian diberikan label merah 
bertuliskan "DESTROY" yang artinya dapat dimusnahkan kemudian dipindahkan di dalam dus di area luar Kardex yang sudah diberi marking floor tape warna merah.

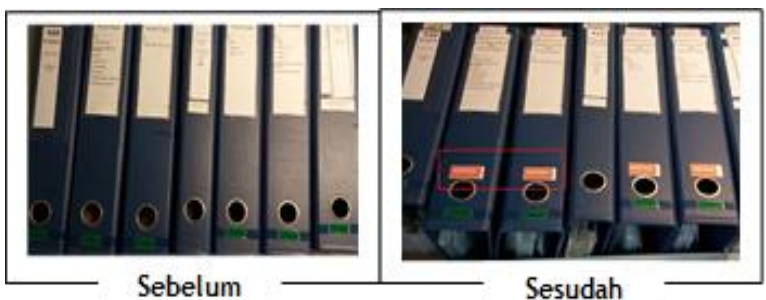

Gambar 7. Pemberian Label Merah "Destroy" pada Ordner

Sedangkan Gambar 8 menunjukkan penggantian ordner menjadi map bening bertali dengan tujuan agar kapasitas penyimpanan dapat menampung lebih banyak ordner. Dapat dilihat pada gambar sebelum masih terlihat area di selasela ordner yang terlihat masih renggang dan kapasitas dalam 1 bin atau kotak hanya dapat menampung sebanyak 8 ordner, setelah diganti dengan map bening bertali dalam 1 bin atau kotak dapat menampung sebanyak 25-30 map bening.

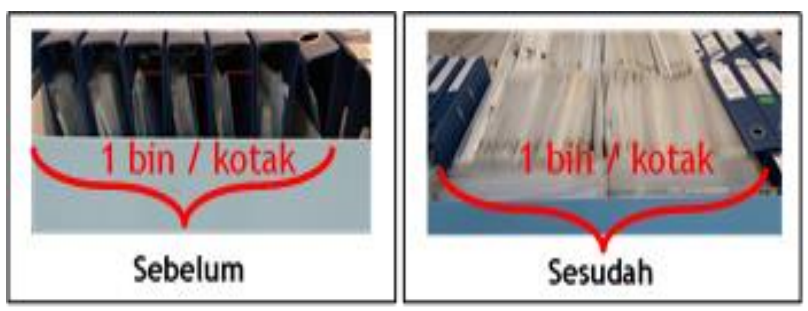

Gambar 8. Penggantian Ordner Sebelum dan Sesudah

Selanjutnya Gambar 9, dilakukan pemindahan dan penyimpanan salah satu jenis dokumen pengembangan analisa yang ada di luar Kardex ke dalam Kardex dengan memanfaatkan area kosong yang tersedia dan merupakan perbaikan dari Tabel 3 nomor 2 dan 3.
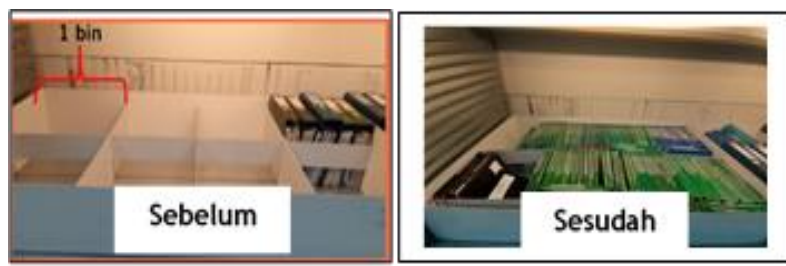

Gambar 9. Area Kosong Bin yang Ada di Tray Kardex

Pada Gambar 10 yang dilakukan adalah memberikan batas area dengan floor tape berwarna untuk membedakan mana yang akan disimpan dan dimusnahkan dan memberikan label berwarna pada setiap dus atau boks yang berisikan informasi yang ada di dalam boks.

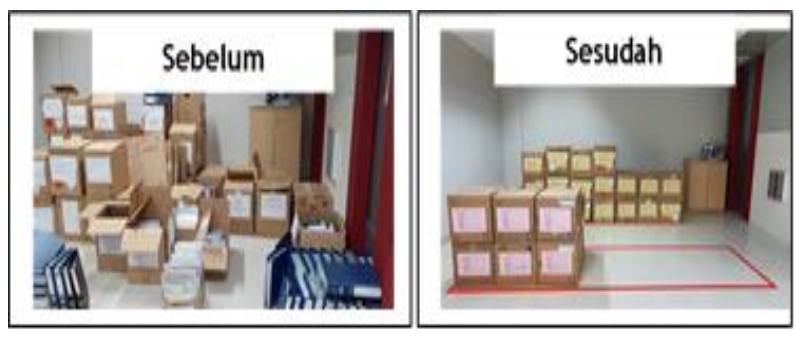

Gambar 10. Pemberian Floor Tape dan Label Box Berwarna

\section{Penerapan 5S Shine (Seiso)}

Hal yang dapat diterapkan dalam tahap 3 dari $5 \mathrm{~S}$ ini yaitu seiso dengan cara membersihkan tempat kerja, menjaga kebersihan sehari-hari, dan memeriksa tempat kerja secara menyeluruh. Beberapa penerapan seiso dalam mengoptimalkan tempat penyimpanan dokumen di kardex dapat dilihat pada Tabel 3.

Tabel 3. Penerapan 5S Shine (Seiso)

\begin{tabular}{|c|c|}
\hline Sebelum perbaikan & Perbaikan \\
\hline \multicolumn{2}{|c|}{$\begin{array}{l}\text { 1. Mengurangi jumlah ordner di dalam } \\
\text { kardex }\end{array}$} \\
\hline $\begin{array}{l}\text { Banyak ditemukan } \\
\text { ordner yang } \\
\text { berdebu dan } \\
\text { berjamur karena } \\
\text { beberapa tray } \\
\text { jarang dibuka. }\end{array}$ & $\begin{array}{l}\text { - Membersihkan } \\
\text { ordner yang berdebu } \\
\text { dan berjamur secara } \\
\text { berkala. }\end{array}$ \\
\hline 2. Mengurangi jumle & ordner di luar kardex \\
\hline $\begin{array}{l}\text { - Area sudut masih } \\
\text { ditemukan debu. } \\
\text { Ditemukan } \\
\text { beberapa doos } \\
\text { untuk menyimpan } \\
\text { dokumen sudah } \\
\text { rusak. }\end{array}$ & $\begin{array}{l}\text { - Membersihkan lantai } \\
\text { di area sudut dll } \\
\text { - Mengganti doos } \\
\text { yang sudah rusak } \\
\text { dengan doos yang } \\
\text { baru agar terlihat } \\
\text { lebih rapi. }\end{array}$ \\
\hline
\end{tabular}

Pada Gambar 11 disini yang dilakukan adalah membersihkan area lantai, sudut, peralatan dan sekitarnya.
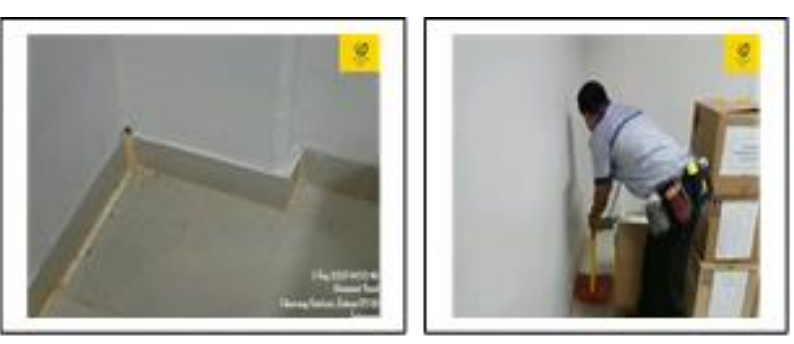

Gambar 11. Pembersihan Area Tempat Penyimpanan di Luar Kardex 
Pada Gambar 12 yang dilakukan adalah membersihkan area dokumen di dalam kardex dari debu atau jamur yang menempel pada ordner dan merupakan perbaikan dari Tabel 4 nomor 2 .
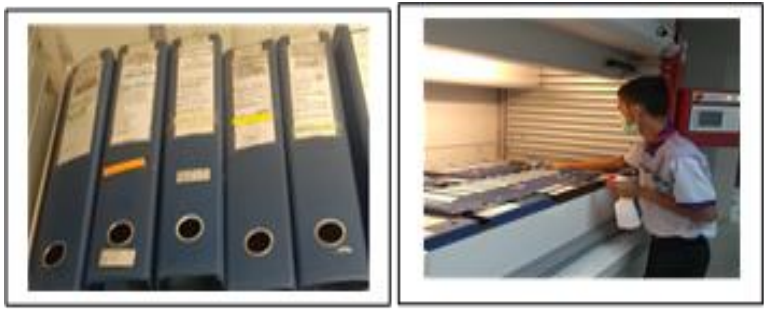

Gambar 12. Pembersihan Area Tempat Penyimpanan di Dalam Kardex

\section{Penerapan 5S Standardize (Seiketsu)}

Hal yang dapat diterapkan dalam tahap 4 dari $5 \mathrm{~S}$ ini yaitu seiketsu dengan cara mempertahankan standar area tempat kerja dalam sebuah organisasi dengan selalu menjaga tetap bersih, tertata dan teratur setiap saat. Untuk menjaganya bisa ditetapkan metode, standar, checklist dan standar warna label. Penerapannya dapat dilihat pada Tabel 4.

Tabel 4. Penerapan 5S Standardize (Seiketsu)

\begin{tabular}{|c|c|}
\hline Sebelum perbaikan & Perbaikan \\
\hline \multicolumn{2}{|c|}{$\begin{array}{l}\text { 1. Mengurangi jumlah ordner di dalam } \\
\text { kardex }\end{array}$} \\
\hline $\begin{array}{l}\text { - Belum ada } \\
\text { database masa } \\
\text { simpan dokumen di } \\
\text { kardex. }\end{array}$ & $\begin{array}{l}\text { - Membuat list } \\
\text { database masa } \\
\text { simpan dokumen di } \\
\text { kardex. }\end{array}$ \\
\hline \multicolumn{2}{|c|}{$\begin{array}{l}\text { 2. Meningkatkan area kosong di dalam } \\
\text { kardex }\end{array}$} \\
\hline $\begin{array}{l}\text { - Belum ada } \\
\text { database area } \\
\text { kosong di dalam } \\
\text { kardex. }\end{array}$ & $\begin{array}{l}\text { - Membuat database } \\
\text { area yang masih } \\
\text { kosong di dalam } \\
\text { kardex yang } \\
\text { terupdate. }\end{array}$ \\
\hline \multicolumn{2}{|c|}{ 3. Mengurangi jumlah ordner di luar kardex } \\
\hline $\begin{array}{l}\text { - Label pada doos } \\
\text { atau box diluar } \\
\text { tempat } \\
\text { penyimpanan } \\
\text { kardex berwarna } \\
\text { putih. }\end{array}$ & $\begin{array}{l}\text { - Membuat standard } \\
\text { warna di area } \\
\text { tempat penyimpanan } \\
\text { dokumen. }\end{array}$ \\
\hline \multicolumn{2}{|c|}{ 4. Mengurangi waktu pencarian dokumen } \\
\hline $\begin{array}{l}\text { - Belum ada } \\
\text { pembeda area yang } \\
\text { disimpan dan } \\
\text { dimusnahkan. }\end{array}$ & $\begin{array}{l}\text { - Memberikan standar } \\
\text { warna di area floor } \\
\text { tape berwarna. }\end{array}$ \\
\hline
\end{tabular}

Pada Tabel 5 yang dilakukan adalah memberikan standar warna di area tempat penyimpanan dokumen yang terdiri dari 3 warna yaitu kuning, hijau dan merah yang berlaku untuk semua area tempat penyimpanan dokumen.

Tabel 5. Standar Warna Area Tempat Penyimpanan Dokumen

\begin{tabular}{ll}
\hline $\begin{array}{c}\text { Standar } \\
\text { warna }\end{array}$ & \multicolumn{1}{c}{ Kategori } \\
\hline Kuning & - Dokumen dalam proses review \\
& - Dokumen disimpan sementara untuk di \\
& simpan dalam kardex \\
& - Dokumen untuk di scan kemudian di simpan \\
& dalam kardex \\
Hijau & - Dokumen sudah selesai di scan dan di \\
& review \\
Merah & - Dokumen yang akan dimusnahkan \\
& - Dokumen untuk di scan musnah \\
& - Dokumen tidak berlaku
\end{tabular}

\section{Penerapan 5S Sustain (Shitsuke)}

Hal yang dapat diterapkan dalam tahap 5 dari 5S ini yaitu shitsuke dengan cara melatih orang untuk berlatih sistem 5S secara terus menerus sehingga menjadi kebiasaan dan tertanam dalam budaya organisasi. Penerapannya dapat dilihat pada Tabel 6 .

Tabel 6. Penerapan 5S Sustain (Shitsuke)

\begin{tabular}{|c|c|}
\hline Sebelum perbaikan & Setelah Perbaikan \\
\hline $\begin{array}{l}\text { - Belum adanya } \\
\text { poster atau stiker } \\
\text { yang ditempel di } \\
\text { area tempat kerja. }\end{array}$ & $\begin{array}{ll}\text { - Membuat poster atau } \\
\text { stiker yang } & \text { ditempel } \\
\text { di area } & \text { terdekat } \\
\text { dengan } & \text { aktivitas } \\
\text { kerja. } & \end{array}$ \\
\hline
\end{tabular}

Pada Gambar 13 dapat dilihat bahwa poster dibuat dengan kata 5S dari bahasa Inggris dan kata $5 \mathrm{R}$ dari bahasa Indonesia untuk memudahkan dibaca dan dipahami oleh karyawan dalam sebuah organisasi atau perusahaan. Diharapkan dengan adanya poster ini dapat mengingatkan karyawan untuk selalu membudayakan 5S / 5R dalam kegiatan sehari-hari. Salah satu perbaikan yang rencananya juga akan dilakukan di masa mendatang terkait dengan sustain adalah melakukan audit $5 S$ secara berkala. Untuk itu, nanti akan dibuatkan SOP audit 5S-nya.

\section{Check}

Pada tahap ketiga dari siklus PDCA ini adalah melakukan analisis dan penilaian terhadap Do apakah terjadi perbaikan sesuai dengan tujuan dari langkah awal siklus PDCA yaitu plan.

\section{Mengurangi jumlah ordner di dalam kardex}

Setelah dilakukan perbaikan dengan menerapkan 5S dari hasil memilah dokumen yang sudah melewati masa simpan diperoleh pengurangan jumlah ordner di dalam Kardex sebanyak 45 ordner atau berkurang sekitar 16\% 
dari jumlah total ordner 7 tray (290 ordner) (Gambar 14).

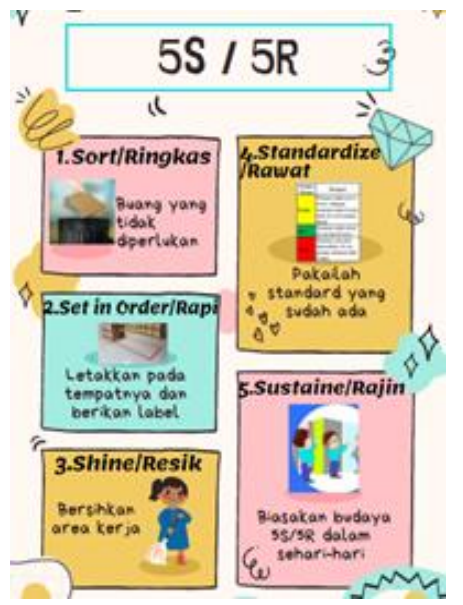

Gambar 13. Gambar Poster 5S / 5R

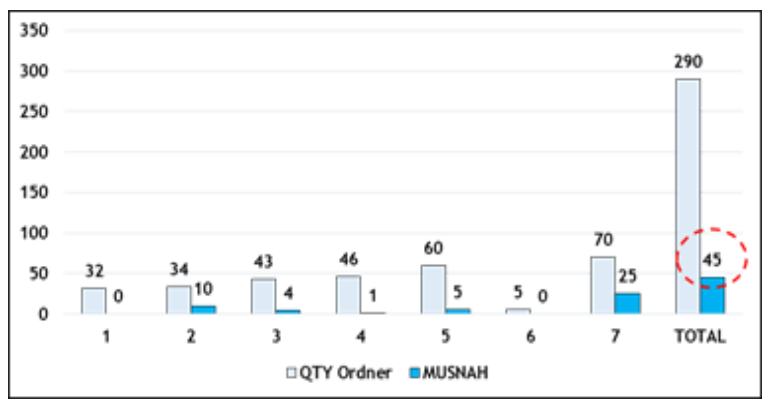

Gambar 14. Dokumen yang Sudah di Cek Masa Simpan

\section{Meningkatkan area kosong di dalam kardex}

Setelah dilakukan perbaikan dengan menerapkan 5S diperoleh peningkatan jumlah area kosong di dalam kardex sebanyak 45 ordner atau meningkat sekitar $21 \%$ dari total area kosong yang dapat dilihat pada Tabel 7.

Tabel 7. Jumlah Ordner Area Kosong di Dalam Kardex

\begin{tabular}{ccc}
\hline Area kosong & Jumlah ordner & $\begin{array}{c}\text { Jumlah Bin } \\
\text { (1 bin }=\mathbf{7} \text { ordner })\end{array}$ \\
\hline $\begin{array}{c}\text { Sebelum di } \\
\text { cek masa } \\
\text { simpan }\end{array}$ & 171 & $171 / 7=24$ bin \\
$\begin{array}{c}\text { Sesudah di } \\
\text { cek masa } \\
\text { simpan } \\
\text { Total }\end{array}$ & 45 & $45 / 7=6$ bin \\
\hline
\end{tabular}

\section{Mengurangi jumlah ordner di luar kardex}

Setelah dilakukan perbaikan dengan menerapkan 5S maka dapat diperoleh jumlah pengurangan ordner yang berada di luar Kardex sebanyak 424 ordner atau berkurang sekitar $77 \%$ dari total ordner di luar Kardex. Pengurangan jumlah ordner dapat di lihat pada Tabel 8.
Tabel 8. Jumlah Ordner di Luar Kardex Setelah Penerapan 5S

\begin{tabular}{cccc}
\hline Jenis Dokumen & $\begin{array}{c}\text { Jumlah } \\
\text { ordner di } \\
\text { awal }\end{array}$ & $\begin{array}{c}\text { Ordner } \\
\text { yang } \\
\text { sudah di } \\
\text { arsip di } \\
\text { kardex }\end{array}$ & $\begin{array}{c}\text { Sisa } \\
\text { jumlah } \\
\text { ordner di } \\
\text { luar } \\
\text { kardex }\end{array}$ \\
\hline $\begin{array}{c}\text { Pengembangan } \\
\text { Formulasi }\end{array}$ & 152 & 26 & 126 \\
$\begin{array}{c}\text { Pengembangan } \\
\text { Analisa }\end{array}$ & 56 & 56 & 0 \\
Kemasan & 342 & 342 & 0 \\
\hline Total & $\mathbf{5 5 0}$ & $\mathbf{4 2 4}$ & $\mathbf{1 2 6}$ \\
\hline
\end{tabular}

\section{Mengurangi waktu pencarian}

Setelah dilakukan penerapan $5 \mathrm{~S}$ maka dapat diperoleh jumlah pengurangan waktu dalam mencari dokumen di luar Kardex. Pada Tabel 9 dapat dilihat waktu yang dibutuhkan untuk mencari dokumen sesudah penerapan 5 S lebih cepat dibandingkan sebelumnya dari 510 detik menjadi hanya 33 detik atau turun $94 \%$ dari waktu sebelumnya

Tabel 9. Waktu Pencarian Dokumen di Luar Kardex

\begin{tabular}{ccccc}
\hline No & $\begin{array}{c}\text { Waktu } \\
\text { sebelum } \\
\text { 5S (detik) }\end{array}$ & $\begin{array}{c}\text { Waktu } \\
\text { sesudah } \\
\text { 5S (detik) }\end{array}$ & $\begin{array}{c}\text { Perbedaan } \\
\text { waktu } \\
\text { (detik) }\end{array}$ & $\begin{array}{c}\text { Persentase } \\
\text { Perbedaan }\end{array}$ \\
\hline 1 & 510 & 33 & 477 & $94 \%$ \\
2 & 120 & 17 & 106 & $88 \%$ \\
3 & 90 & 13 & 77 & $86 \%$ \\
\hline
\end{tabular}

\section{Action}

Pada tahap keempat atau terakhir dari siklus PDCA ini adalah melakukan penilaian atau membandingkan hasil dari tahap check dengan tujuan dari langkah awal siklus PDCA yaitu plan apakah terjadi perbaikan yang signifikan atau tidak, apabila tidak menunjukkan peningkatan, maka plan alternatif harus dikembangkan dan siklusnya akan terus berlanjut.

\section{Hasil perbaikan}

Setelah dilakukan perbaikan dengan menerapkan 5S dan siklus PDCA maka perlu dilakukan penilaian apakah perbaikan tempat penyimpanan sudah optimal. Pada Gambar 15 dapat dilihat pada periode 2020 jumlah ordner meningkat dari 4529 menjadi 4908 ordner atau $104 \%$ dari batas maksimal kapasitas di dalam kardex (4700 ordner) artinya sudah dijalankan secara optimal.

Dari hasil memilah dokumen yang sudah melewati masa simpan di dalam Kardex dari 290 dan 907 ordner didapatkan jumlah ordner yang dapat dimusnahkan pada setiap periode secara berkala. Gambar 16 memperlihatkan hasil pengecekan dokumen yang sudah melewati masa simpan periode Mei sampai Agustus 2020 dan 
periode 2020 dapat dilihat dokumen yang dapat dimusnahkan ada 45 ordner.

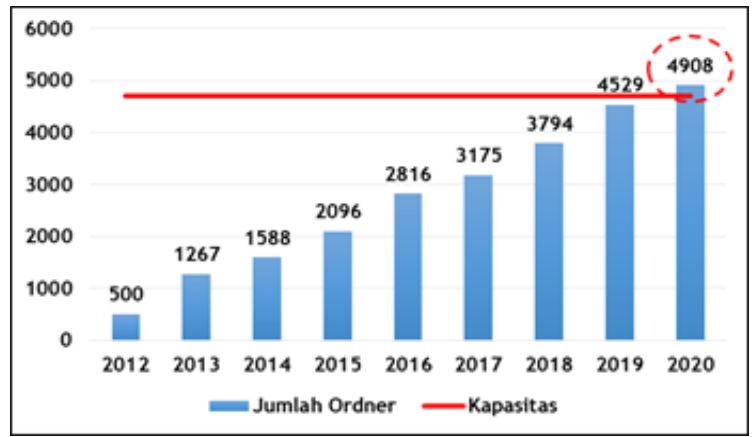

Gambar 15. Jumlah Ordner di Dalam Kardex 2020

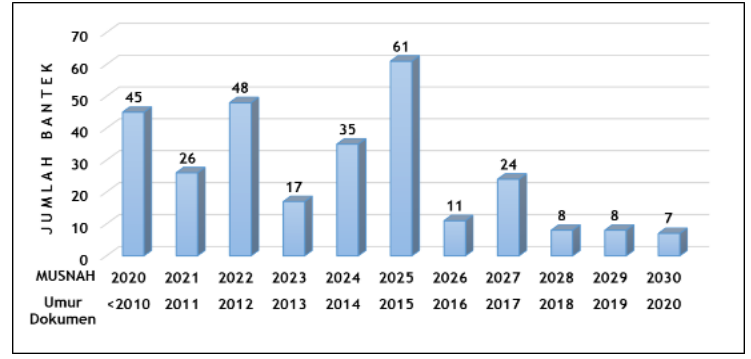

Gambar 16. Pemusnahan Dokumen secara Berkala 290 Ordner

Gambar 17 menunjukkan hasil pengecekan dokumen yang sudah melewati masa simpan pada periode Mei sampai Maret 2021 dan pada tahun 2020 dapat dilihat dokumen yang dapat dimusnahkan meningkat sebanyak 228 ordner.

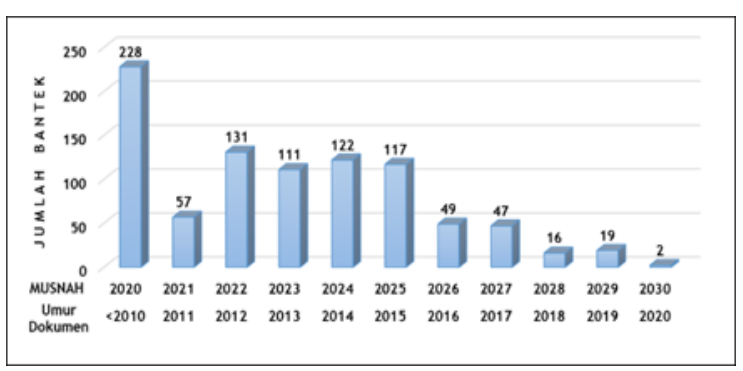

Gambar 17. Pemusnahan Dokumen secara Berkala 907 Ordner

\section{Pengelolaan dokumen}

Pengelolaan dokumen merupakan cara mengelola atau mengatur dokumen mulai dari penerimaan, penyimpanan, scan, peminjaman, pencatatan hingga pemusnahan dokumen. Selain itu juga mempertimbangkan alat perlengkapan apa saja yang cocok untuk menyimpan dokumen disesuaikan dengan kebutuhan tebal tipisnya dokumen dan efisien baik secara biaya maupun kapasitas. Pengelolaan dokumen diperbaiki dan dapat digambarkan dalam bentuk flowchart sebagaimana terlihat pada Gambar 18.

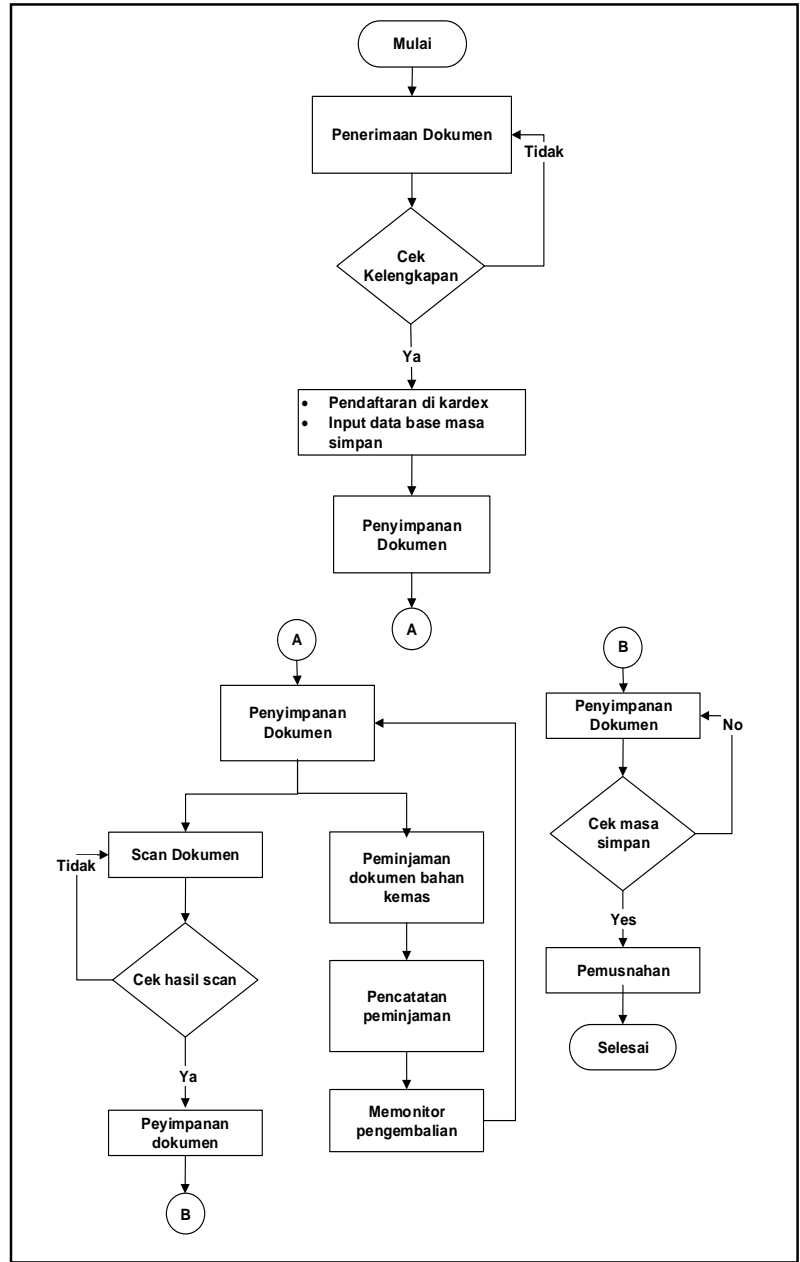

Gambar 18. Flowchart Pengelolaan Dokumen

\section{Perhitungan Cost Saving}

Material terbanyak yang sering digunakan saat menyimpan dokumen adalah ordner. Agar dapat mengoptimalkan tempat penyimpanan diperlukan material pengganti ordner yang memiliki fungsi yang hampir sama. Material pengganti ordner adalah map bening yang harganya lebih murah, bahan dari plastik, tidak tebal dan dapat mengisi penuh. Pada Tabel 10 dengan adanya penggantian material dari ordner menjadi map bening dapat menghemat biaya sebesar Rp 5.168.160 atau 79,90\%.

Tabel 1. Perbandingan Harga

\begin{tabular}{|c|c|c|c|c|}
\hline Item & Satuan & $\begin{array}{c}\text { Harga/ } \\
\text { pcs }\end{array}$ & $\begin{array}{c}\text { Kebutu } \\
\text { han/ } \\
\text { Tahun }\end{array}$ & Biaya/Tahun \\
\hline Ordner & $\begin{array}{c}1 \text { pcs } \\
1 \text { pack }=12\end{array}$ & Rp 26.950 & 240 & Rp 6.468.000 \\
\hline $\begin{array}{c}\text { Map } \\
\text { Bening }\end{array}$ & $\begin{array}{c}\text { pcs } \\
\text { Harga/pack= } \\
\text { Rp } 65.000 \\
\text { Harga/pcs= } \\
\text { Rp65.000/12= } \\
\text { Rp 5.416 }\end{array}$ & Rp 5.416 & 240 & $\operatorname{Rp} 1.299 .840$ \\
\hline \multicolumn{4}{|c|}{ Selisih } & $\operatorname{Rp} 5.168 .160$ \\
\hline
\end{tabular}




\section{Rangkuman Perbaikan}

Berdasarkan hasil analisis dan perbaikan perubahan terbesar terdapat pada periode 2020 jumlah ordner di dalam kardex meningkat dari 4529 menjadi 4908 ordner atau $104 \%$ yang artinya tempat penyimpanan sudah optimal. Dan perubahan terkecil terdapat pada mengurangi jumlah ordner di dalam kardex, karena perbaikan yang dilakukan baru tahap 1 sebesar $24 \%$ dari total dokumen dengan status FINISH sebesar 1184 ordner. Untuk itu tetap diperlukan perbaikan berkelanjutan karena pentingnya pengelolaan sehingga alur keluar masuknya dokumen terus berjalan. Penelitian sebelumnya dengan menerapkan metodologi $5 S$ dapat meningkatkan keselamatan, produktivitas, efisiensi dan pemeliharaan dan tujuan yang dicapai adalah meningkatkan tempat penyimpanan sebesar $30 \%$, mengurangi waktu tidak produktif sebesar $10 \%$ (Agrahari et al., 2015). Penurunan cacat dengan menggunakan metode Lean Manufacturing dan PDCA dapat menurunkan biaya produksi sebesar 38\% (Azwir \& Setyanto, 2017).

\section{KESIMPULAN}

Berdasarkan hasil perbaikan yang dilakukan dengan analisis menggunakan siklus PDCA untuk mengoptimalkan tempat penyimpanan, maka dapat disimpulkan sebagai berikut: (1) Adanya pengecekan masa simpan dokumen di dalam Kardex dapat mengurangi penumpukan dokumen di dalam Kardex dari 7 tray atau 290 terdapat 45 ordner atau $16 \%$ yang dapat dimusnahkan dan meningkatkan jumlah area kosong 171 menjadi 216 ordner atau 21\%, (2) Perapihan dokumen di luar Kardex dan pemindahan ke dalam Kardex dapat mengurangi jumlah ordner yang berada di luar Kardex sebanyak 424 ordner atau $77 \%$ dan waktu yang dibutuhkan untuk mencari dokumen lebih cepat dari 510 detik menjadi 33 detik atau $94 \%$, (3) Penggantian ordner menjadi map bening dapat memperbanyak kapasitas jumlah ordner dalam 1 bin dari 8 produk menjadi $25-30$ produk, dan menghemat biaya sebesar Rp 5.168.160 atau $79,90 \%$, (4) Pembuatan database masa simpan dokumen yang ada di Kardex, menjadikan pemusnahan dokumen pada periode berikutnya dapat dijalankan secara otomatis dan periodik.

Saran untuk peneliti selanjutnya dan perusahaan adalah: (1) Pada tahap Check perlu dilakukan perbaikan dengan menerapkan audit 5S melalui pembentukan dewan 5S, (2) Pada tahap Action perlu dilakukan perbaikan dengan memberikan penghargaan terhadap karyawan setelah dibentuknya dewan 5S, (3) Pada cost saving perlu dilakukan perhitungan biaya jika ada penambahan area penumpukkan dokumen atau biaya sewa penitipan dokumen di luar perusahaan jika tempat penyimpanan sudah tidak memadai sehingga jumlah cost saving menjadi lebih besar.

\section{DAFTAR PUSTAKA}

Adyatama, A., \& Handayani, N. U. (2018). Perbaikan Kualitas Menggunakan Prinsip Kaizen Dan 5 Why Analysis: Studi Kasus Pada Painting Shop Karawang Plant 1, Pt Toyota Motor Manufacturing Indonesia. J@ti Undip: Jurnal Teknik Industri, 13(3), 169176. https://doi.org/10.14710/jati.13.3.169176

Agrahari, R. S., Dangle, P. A., \& Chandratre, K. V. (2015). Implementation of 5S methodology in the small scale industry: A case study. International Journal of Scientific \& Technology Research, 4(4), 180-187. https://www.ijstr.org/finalprint/apr2015/Implementation-Of-5sMethodology-In-The-Small-Scale-IndustryA-Case-Study.pdf

Azwir, H. H., \& Satriawan, H. (2018). Analisis jam kerja efektif dalam upaya peningkatan produktivitas tenaga kerja dengan metode PDCA di PT NMI. Spektrum Industrl, 16(1), 65-76.

https://doi.org/10.12928/si.v16i1.9781

Azwir, H. H., \& Setyanto, A. K. (2017). Analisis Penerapan Lean Manufacturing Pada Penurunan Cacat Feed Roll Menggunakan Metode PDCA (Studi Kasus PT. XYZ). Jurnal Rekayasa Sistem Industri, 6(2), 105118. https://doi.org/10.26593/jrsi.v6i2.2714.105118

Darmawan, H., Hasibuan, S., \& Hardi Purba, H. (2018). Application of Kaizen Concept with 8 Steps PDCA to Reduce in Line Defect at Pasting Process: A Case Study in Automotive Battery. International Journal of Advances in Scientific Research and Engineering, 4(8), 97-107. https://doi.org/10.31695/IJASRE.2018.3280 0

De Casanove, O., \& Sèdes, F. (2021). Guidelines for Security Education, Training and Awareness: a literature review. https://hal.archives-ouvertes.fr/hal03249016/

Fajri, H., \& Syahyuman, S. (2012). Sistem Pengelolaan Arsip Dinamis Aktif di Kantor Perpustakaan, Arsip, dan Dokumentasi Kabupaten Pesisir Selatan. IImu Informasi Perpustakaan Dan Kearsipan, 1(1), 409417.

http://ejournal.unp.ac.id/index.php/iipk/articl e/view/1534 
Gapp, R., Fisher, R., \& Kobayashi, K. (2008). Implementing $5 S$ within a Japanese context: an integrated management system. Management Decision, 46(4), 565-579. https://doi.org/10.1108/0025174081086506 7

Huang, L., Lu, C., Pang, M., Li, L., Zhang, Y., Su, A., \& Ding, L. (2021). Effect of PDCA-based nursing intervention on activities of daily living, neurological function and selfmanagement in acute cerebral stroke. American Journal of Translational Research, 13(5), 5315-5321. https://www.ncbi.nlm.nih.gov/pmc/articles/P MC8205731/

Isniah, S., Hardi Purba, H., \& Debora, F. (2020). Plan do check action (PDCA) method: literature review and research issues. Jurnal Sistem Dan Manajemen Industri, 4(1), 72 81. https://doi.org/10.30656/jsmi.v4i1.2186

Jiang, L., Sun, X., Ji, C., Kabene, S. M., \& Abo Keir, M. Y. (2021). PDCA cycle theory based avoidance of nursing staff intravenous drug bacterial infection using degree quantitative evaluation model. Results in Physics, 26, 104377.

https://doi.org/10.1016/j.rinp.2021.104377

Kaniecka, E., Timler, D., Białas, A., Timler, M., Białas, M., Staszewska, A., \& RybarczykSzwajkowska, A. (2021). EN ISO 9001: 2015 Quality Management System for Health Care Sector in Accordance with PN-EN 15224: 2017-02 Standard and Accreditation Standards of the Minister of HealthComparative Analysis. Journal of Health Study And Medicine, 1, 41-66. https://doi.org/10.36145/JHSM2021.03

Kumar, K., \& Kumar, S. (2012). Steps for implementation of 5S. International Journal of Managment, IT and Engineering, 2(6), 402-416.

https://www.indianjournals.com/ijor.aspx?tar get $=$ ijor:ijmie $\&$ volume $=2 \&$ issue $=6 \&$ article $=0$ 32

Kusumawardhani, K., Handiyani, H., \& Nurdiana, N. (2021). Pengembangan Tools untuk Mengatasi Kepadatan Pasien di Instalasi
Gawat Darurat. Journal of Telenursing (JOTING), 3(1), 276-285. https://journal.ipm2kpe.or.id/index.php/JOTI $\mathrm{NG} /$ article/view/2263

Mitra, A. (2016). Fundamentals of quality control and improvement. New York: Springer Publishing Company. https://books.google.co.id/books?id=OqjLC gAAQBAJ

Muhidin, S. A., Winata, H., \& Santoso, B. (2016). Pengelolaan arsip digital. JPBM (Jurnal Pendidikan Bisnis Dan Manajemen), 2(3), 178-183.

http://journal2.um.ac.id/index.php/jpbm/articl e/view/1708

Nelfiyanti, N., Casban, C., Casban, C., Ridwan, R., \& Ridwan, R. (2020). Decreasing Scratch Defects with Qcc Methods on the Line Assembly Frame of the Motorcycle Unit in PT. XYZ. Spektrum Industri, 18(2), 167-174. https://doi.org/10.12928/si.v18i2.17918

Realyvásquez-Vargas, A., Arredondo-Soto, K., Carrillo-Gutiérrez, T., \& Ravelo, G. (2018). Applying the Plan-Do-Check-Act (PDCA) Cycle to Reduce the Defects in the Manufacturing Industry. A Case Study. Applied Sciences, 8(11), 1-17. https://doi.org/10.3390/app8112181

Suprayitno, S., \& Sumarno, S. (2019). Arsip Dan Retensi Analisis Isi Jadwal Retensi Arsip Kementerian Ketenagakerjaan. Jurnal Kearsipan, 13(2), 139-156. https://doi.org/10.46836/jk.v13i2.48

Visco, D. (2017). 5S Made Easy: A Step-by-Step Guide to Implementing and Sustaining Your 5S Program. Taylor \& Francis. https://books.google.co.id/books?id=XeCYC gAAQBAJ

Wajdi, F., \& Wiguna, D. (2015). Pengukuran dan Intervensi Pengendalian Kualitas Pengelasan Blast Furnace Shell dengan Metode Plant, Do, Check Action (PDCA). Jurnal INTECH Teknik Industri Universitas Serang Raya, 1(1), 15-23. https://ejurnal.Ippmunsera.org/index.php/INTECH/ar ticle/view/152 